\title{
PROCESSO DE TRABALHO E SERVIÇO SOCIAL: DILEMAS, EMBATES E LIMITAÇÕES
}

\author{
Jonis Manhães Sales Felippe \\ Universidade Federal do Rio de Janeiro - UERJ - Brasil \\ Isabela Sarmet de Azevedo \\ Universidade Federal Fluminense - UFF - Brasil
}

\section{Resumo}

Tomando a categoria processo de trabalho em Marx como ponto de partida, este artigo resgata algumas das principais aproximações entre tal estrutura conceitual e a profissão serviço social. Para tanto, foram analisadas as produções de importantes intelectuais (iamamoto, 2010; almeida, 1996; barbosa, cardoso e almeida, 1998; granemann, 1999; cardoso et. Al. 1997; lessa, 2007) que se propuseram a discutir o tema, evidenciando as limitações, os embates e os dilemas entre as suas obras. Concomitantemente, recorre-se aos elementos clássicos da tipologia marxiana, bem como ao debate sobre o ramo de serviços para demonstrar as fragilidades de algumas dessas apropriações e apontar novos caminhos reflexivos.

Palavras-chave: Serviço Social; processo de trabalho; serviços.

\section{Introdução}

Um dos debates de maior destaque no Serviço Social atualmente se refere à relação entre este e a categoria processo de trabalho. Desde que a tese que compreende a profissão como uma especialização do trabalho ganhou corpo e se difundiu no interior da categoria, sendo adotada como fundamento das Diretrizes Curriculares da ABEPSS $^{1}$ na década de 1990, diversos intelectuais têm se proposto a descrever a atividade profissional a partir dos elementos básicos do processo de trabalho em geral formulados por Marx (2013).

Acontece que, pelas próprias peculiaridades das funções e das atribuições dessa ocupação, bem como pela historicidade e especificidade da categoria marxiana, esse não tem sido um terreno de consensos entre os autores. Principalmente a partir dos anos 2000, com as produções de Sérgio Lessa (2007), as reflexões ganharam novo fôlego e novos caminhos de interpretação.

\footnotetext{
${ }^{1}$ Associação Brasileira de Ensino e Pesquisa em Serviço Social.
} 
Nessa direção, o texto que apresentado busca resgatar as principais formulações no âmbito do Serviço Social que se dedicaram ao estudo do tema, contrapondo suas posições, ideias, contradições e embates. Não obstante, mais do que uma simples revisão, desenvolve-se neste artigo um diálogo crítico, que possibilita a inclusão e o levantamento de novos elementos para a análise.

O objetivo em voga não é apenas o de demonstrar a estrutura e as possíveis limitações e imprecisões do estado da arte sobre o assunto, mas também o de suscitar a preocupação com a real contribuição que tal debate tem oferecido para se construir e/ou se repensar a prática profissional do Serviço Social. Destarte, cabe indagar: Será que o caminho percorrido pelos autores está alinhado às situações e às necessidades concretas da categoria, ou seria mais um debate puramente teórico e restrito ao âmbito acadêmico?

\section{As diferentes abordagens sobre o tema}

Em 1982, Marilda Iamamoto publicou um dos textos de maior influência no Serviço Social brasileiro até os dias atuais, o qual compôs a primeira parte do livro Relações Sociais e Serviço Social no Brasil: esboço de uma interpretação teórico-metodológica, construído em parceria com Raul de Carvalho (IAMAMOTO e CARVALHO, 2009). Nessa clássica obra, a principal tese da autora é o reconhecimento da aludida profissão como trabalho ou como especialização do trabalho coletivo. Para chegar a tal constatação, a professora percorre um longo caminho, fundamentando suas argumentações primordialmente nos textos de Karl Marx.

Com o objetivo de situar o Serviço Social no interior das relações sociais e, consequentemente, na dinâmica do trabalho, ela parte do conceito de produção social, que não deve ser compreendido como a simples confecção de objetos materiais, mas, essencialmente, como um conjunto de relações sociais entre pessoas em determinadas condições históricas (Idem, p. 30). A partir dessa perspectiva, o capitalismo é visto como uma forma determinada de os homens se relacionarem para produzir e reproduzir as suas condições materiais e espirituais (ideias, representações, valores) de vida. Essa modalidade histórica de produção social, na qual o objetivo central é a troca e a construção de valores, subentende uma organização do trabalho também diferenciada, bem como a existência de 
novas especializações que atendam às demandas que surgem com a sua instauração e consolidação.

Para destacar as características peculiares do modo de produção capitalista, especialmente a forma como o trabalho é organizado no seu interior, a publicação de 1982 reconstrói o percurso expositivo elaborado no livro I de O capital (MARX, 2013). Parte, portanto, do elemento mais simples encontrado no capitalismo, a mercadoria, identificando a forma como ela é produzida (fundada no assalariamento e na concentração privada dos meios de vida e de produção), até chegar à totalidade da vida social, apontando os fundamentos da exploração e da desigualdade e os mecanismos ideológicos que garantem a permanência e a legitimação dessa estrutura social.

Considerando toda essa dinâmica, é lançado o desafio de capturar o significado e as funções do Serviço Social no interior das relações capitalistas, considerando-o como um tipo de trabalho especializado, que surge para atender a necessidades sociais derivadas do antagonismo entre as classes fundamentais (capitalistas e trabalhadores). Embora, na maioria dos casos, não atue diretamente nos processos de produção do valor, sua intervenção compõe "uma gama de atividades, que, não sendo diretamente produtivas, são indispensáveis ou facilitadoras do movimento do capital” (IAMAMOTO E CARVALHO, 2009, p. 86).

A adoção de tais pressupostos leva Marilda Iamamoto a inaugurar uma nova discussão no interior da categoria. Enfatizando o processo de institucionalização dessa profissão, vinculado ao crescimento do Estado, das instituições prestadoras de serviços sociais e das políticas de racionalização e vigilância dos empregados nas empresas, a autora desmistifica as conexões entre as atividades desenvolvidas pelos assistentes sociais e as motivações de ordem vocacional, próprias das marcas religiosas deixadas pela origem vinculada à Igreja Católica. Ganham destaque as determinações objetivas que conferem materialidade a essa prática, em especial o assalariamento da sua mão de obra.

Nessa direção, na tentativa de analisar a profissão pelo prisma da categoria trabalho, dentro da dinâmica capitalista, a professora define as características essenciais que permitem tal associação. Em primeiro lugar, o assistente social é visto como trabalhador predominantemente improdutivo, pois, como já foi ressaltado, a sua força de trabalho não gera diretamente novos produtos, novos valores ${ }^{2}$ (Idem, p. 86).

\footnotetext{
${ }^{2}$ Cabe destacar que, para Marx (2004), é trabalho produtivo toda atividade que esteja inserida em um processo de trabalho especificamente capitalista (processo de valorização), que seja empregado com vistas à produção de mais-valor, gere ela um produto material ou não.
} 
Por meio da prestação de serviços e benefícios (distribuição de parte dos valores produzidos pelos próprios trabalhadores e apropriados pela empresa ou pelo Estado) e da realização de ações educativas e de controle, o Serviço Social contribui para o aumento da produtividade da força de trabalho e para a amenização de situações que possam comprometer a manutenção das relações de exploração, segundo as colocações da escritora. É justamente nesse quesito que estaria o valor de uso das ações desempenhadas pelos assistentes sociais, uma vez que o caráter econômico das funções por eles desempenhadas está subordinado à dimensão política da sua prática (IAMAMOTO, 2004; IAMAMOTO E CARVALHO, 2009).

Em segundo lugar, e aqui se encontra o elemento mais importante para a análise sugerida neste artigo, são lançados os pressupostos que fundamentarão as relações que Marilda Iamamoto (2010) estabelece entre o Serviço Social e a concepção de processo de trabalho na teoria marxiana.

Ao tratar dos valores de uso, Marx (2013) decompõe os elementos que participam da sua produção, em especial o trabalho, que, na sua obra, é definido como a atividade teleológica (adequada a um fim) por meio da qual o homem transforma a natureza em uma forma útil para a sua própria vida. Segundo o pensador, todo trabalho é um processo em que comparecem os seguintes elementos: 1) a atividade humana orientada a um fim (o próprio trabalho); 2) o objeto de trabalho (matéria sobre a qual aquela atividade aplicar-se-á); 3) os meios de trabalho (instrumentais ou conjunto de elementos que se colocam entre o homem e o objeto de trabalho).

Essa classificação se tornou célebre nas discussões críticas sobre o tema. No Serviço Social, tais pressupostos também foram adotados como base de sustentação por Marilda Iamamoto (2004 e 2010) para desenvolver suas argumentações na defesa da referida profissão como trabalho. Assim, buscou a professora definir os elementos constitutivos do processo de trabalho do assistente social (objeto e meios, conforme a tipologia clássica exposta), mesmo afirmando em alguns trechos que o Serviço Social é uma prática inserida em processos de trabalho (Idem, 2010, p. 19; 2012, p. 429) - o que gera certas ambiguidades nos textos. ${ }^{3}$

Do ponto de vista da autora, o objeto de trabalho ou a matéria-prima do Serviço Social é a questão social, uma vez que esta é o elemento que provoca a necessidade da intervenção do assistente social. Em suas palavras, a questão social deve ser apreendida como

\footnotetext{
${ }^{3}$ Toda a exposição de Iamamoto (2010) leva à compreensão de que o Serviço Social, ou mesmo o assistente social, possui um processo de trabalho próprio, já que são definidos o seu objeto e os seus meios de trabalho. No entanto, em diversos momentos (Idem, 2010 e 2012), a autora afirma que a profissão se insere em processos de trabalho, sendo parte de um trabalhador coletivo/combinado.
} 
[...] o conjunto das expressões das desigualdades da sociedade capitalista madura, que tem uma raiz comum: a produção social é cada vez mais coletiva, o trabalho torna-se mais amplamente social, enquanto a apropriação dos seus frutos mantém-se privada, monopolizada por uma parte da sociedade (Idem, 2010, p. 27).

Já os meios de trabalho são definidos como "o conjunto de conhecimentos e habilidades adquiridos pelo assistente social ao longo do seu processo formativo" (Idem., p. 63). Entretanto, a intelectual esclarece sucintamente que ele é apenas parte dos meios de trabalho, visto que o Serviço Social não detém todos os recursos necessários para a realização de suas funções, sendo uma profissão regulamentada como liberal, mas que não se realiza como tal. Uma parcela substancial dos recursos técnicos, financeiros e humanos é administrada pelas instituições empregadoras. Por se tratar de um trabalhador assalariado, essa condição interfere diretamente na realização de suas atividades profissionais, organizando o processo de trabalho do qual o assistente social participa, o que fundamenta a tese segundo a qual a autonomia do assistente social é relativa.

Por último, o esforço de Marilda Iamamoto se concentra na tentativa de definição do produto do trabalho do assistente social, recorrendo novamente às formulações de Marx (2013) para decifrar os valores de uso, as qualidades derivadas do caráter concreto do trabalho do assistente social e os resultados "não materiais" da sua prática, ou seja, as contribuições que ele oferece para o processo de acumulação do capital ao participar da reprodução da força de trabalho e das relações sociais em geral (reafirmando as discussões iniciadas no texto lançado em 1982, conforme já foi apresentado). O produto do seu trabalho seria, por conseguinte, desfrutado como um serviço ${ }^{4}$, esgotando-se em si mesmo ao difundir efeitos políticos e ideológicos na vida cotidiana dos demais trabalhadores, o que interfere diretamente nos resultados da produção.

Cabe destacar que, de maneira geral, a palavra serviço, como indica Costa (2010), está relacionada às atividades que são usufruídas na relação direta entre o trabalhador e o consumidor, sendo a expressão do valor de uso de um trabalho particular desfrutado em si mesmo, e não no corpo de um objeto material. Complementando tal compreensão, Braverman (1987, p. 303- 304), ao tratar dos serviços no capitalismo, esclarece que os resultados do trabalho nesse setor (considerando que a produção e o consumo de um serviço são fenômenos simultâneos)

\footnotetext{
${ }^{4}$ Para aprofundar as discussões sobre serviços, considerando a gama diversificada de atividades que são incluídas nessa denominação, ver Mandel (1985), Braverman (1987) e Mota (1998).
} 
[...] não servem para constituir um objeto vendável que encerre seus efeitos úteis como parte de sua existência na forma de mercadoria. Ao invés, os próprios efeitos do trabalho transformam-se em mercadoria. Quando o trabalhador não oferece esse trabalho diretamente ao usuário de seus efeitos, mas, ao invés, vende-o ao capitalista, que o revende no mercado de bens, temos então o modo de produção capitalista no setor de serviços.

Voltando aos argumentos de Iamamoto (2010), alguns apontamentos tornam-se importantes para analisar com precisão essa etapa da reflexão por ela apresentada. Como se pode observar no estudo desenvolvido por Marx (2013), ao tratar do processo de trabalho em geral, tal autor se refere apenas ao trabalho gerador de produtos concretos, de valores de uso materiais a partir da modificação da natureza.

O processo de trabalho, que descrevemos em seus elementos simples e abstratos, é
uma atividade regida com o fim de criar valores de uso, de apropriar os elementos
naturais às necessidades humanas; é condição necessária do intercâmbio material
entre o homem e a natureza; é condição natural eterna da vida humana, sem
depender, portanto, de qualquer forma dessa vida, sendo antes comum a todas as
suas formas sociais. Não foi, por isso, necessário tratar do trabalhador em sua
relação com os outros trabalhadores. Bastaram o homem e seu trabalho, de um lado;
a natureza e seus elementos materiais, do outro. (MARX, 2013, p. 218).

O objetivo do pensador alemão, nesse caso, é o de discutir o trabalho sobre seu aspecto comum a todas as formações sociais, como atividade intrínseca e necessária à sobrevivência humana. Nesse sentido, parece extremamente arriscado transportar tal estrutura categorial para compreender um tipo de atividade que, de acordo com a própria Iamamoto (2004, 2010, 2012), surge especificamente no capitalismo, é majoritariamente improdutiva, atua na esfera da reprodução social e tem como principais produtos/resultados efeitos sociais, “coisas" não corporificadas (Idem, 2010, p. 68).

Mesmo que possuam conexões profundas, as esferas da produção e da reprodução social não são idênticas, visto que a primeira está relacionada à construção das mercadorias e da riqueza; a segunda, à reposição da força de trabalho, à sociabilidade, à construção e à perpetuação dos valores e ideologias, conforme salienta Granemann (1999). Outrossim, as atividades que atuam na esfera da reprodução não transformam objetos materiais, não se relacionam diretamente com a natureza e, portanto, não geram produtos, se considerada a conceituação formulada por Marx (2013, p. 214): “o produto é um valor de uso, um material da natureza adaptado às necessidades humanas através da mudança de forma. $O$ trabalho está incorporado ao objeto sobre que atuou" (grifos nossos).

Como fica evidente, o objeto tratado pelo autor europeu, ao falar do processo de trabalho, é especificamente um bem de origem material e natural a ser modificado pela ação 
teleológica humana, mesmo quando filtrado pelo trabalho, no caso da matéria-prima. Como poderia ser a questão social, dentro dessa linha de raciocínio, considerada o objeto do Serviço Social se se trata de um fenômeno eminentemente social e não palpável? Quais são as mudanças que a atividade realizada pelo assistente social, potencializada pelos seus meios de trabalho, promovem na questão social? Que novo produto/mercadoria essas modificações geram a partir da transformação do objeto?

Difícil seria responder a tais perguntas, uma vez que a estrutura categorial ${ }^{5}$ formulada por Marx (2013) não foi elaborada para tratar da esfera da reprodução. Por outro lado, o próprio conceito de questão social não facilita a elucidação das questões, pois, como apontou Netto (2007), trata-se de um objeto sincrético, multifacetado, polimórfico e que envolve todos os aspectos da vida societária. Alguns autores chegam a questionar a viabilidade da sua utilização para designar o objeto do Serviço Social.

Se for entendida [a questão social] como sendo as contradições do processo de acumulação capitalista, seria, por sua vez, contraditório colocá-la como objeto particular de uma profissão determinada, já que se refere a relações impossíveis de serem tratadas profissionalmente, através de estratégias institucionais/ relacionais próprias do próprio desenvolvimento das práticas do Serviço Social. Se forem as manifestações dessas contradições o objeto profissional, é preciso também qualificálas para não colocar em pauta toda a heterogeneidade de situações, que, segundo Netto, caracteriza, justamente, o Serviço Social (FALEIROS, 1997, p. 37).

No que tange à classificação do trabalho exercido pelo assistente social como produtivo ou como improdutivo, novas questões se afiguram nesse contexto. Ainda que se considere tal profissional atuando na esfera da produção, realizando uma atividade produtiva (no caso dos empregados de setor privado, seja ele de bens materiais ou serviços, como sugere Iamamoto (2004, 2010 e 2012)), o problema não está resolvido, mas ampliado. Sendo sua força de trabalho comprada pelo capitalista e produtora de mais-valia, o tempo de trabalho excedente expropriado do assistente social se soma ao expropriado dos demais trabalhadores ${ }^{6}$ e deveria ser incorporado ao valor do produto final para que seja realizado na circulação (na troca).

Como salienta Marx (2004), quando se consideram a máquina e as atividades produtivas, tanto os que trabalham com a mão quanto os que trabalham com a cabeça participam da formação da mercadoria. Nesse caso, o objeto do trabalho do Serviço Social, se este é visto como uma atividade produtiva, deveria ser o mesmo objeto dos demais trabalhadores, assim como o produto final deveria compartilhado (já que foi elaborado pelo

\footnotetext{
${ }^{5}$ Considera-se nesse aspecto a questão especificamente relacionada ao tema processo de trabalho.

${ }^{6}$ Ou seja, compõe a massa de valor gerada pelo chamado trabalhador coletivo. (IAMAMOTO, 2012).
} 
trabalhador coletivo). Numa empresa automobilística, por exemplo, os objetos/matériasprimas do Serviço Social (membro do trabalhador coletivo) seriam os metais, plásticos e vidros, e o produto final seria o carro. Embora lógico, esse raciocínio não parece muito aceitável, não sendo desenvolvido por Iamamoto (2010).

Como se sabe, porém, os assistentes sociais não atuam, na sua maioria, nas empresas privadas, mas no serviço público (CFESS, 2005). Dessa maneira, as ações por eles desenvolvidas, além de pertencerem à esfera da reprodução (não gerarem um bem material), são serviços improdutivos, o que firma a necessidade de pensar o seu trabalho partindo de outros elementos estruturantes, que não os relacionados à transformação da natureza para a satisfação de necessidades, como propõe Marx (2013) ao tratar do processo de trabalho.

Partindo dessa mesma lógica adotada por Iamamoto (2010 e 2012), outros autores também se propuseram a debater e aprofundar a (im) pertinência da relação entre o Serviço Social e a categoria processo de trabalho. A despeito de algumas diferenças entre as abordagens, destacam-se os artigos de Almeida (1996), Barbosa, Cardoso e Almeida (1998), Granemann (1999) e Cardoso et. al. (1997).

Granemann (1999) e Cardoso et. al. (1997), por exemplo, ressaltam os mesmos elementos enfatizados por Iamamoto e Carvalho (2009) e Iamamoto (2004 e 2010): definem trabalho com base na relação com a natureza; enumeram os elementos do processo de trabalho segundo Karl Marx; enfatizam as particularidades do capitalismo; salientam o caráter assalariado das funções desempenhadas pelo assistente social; diferenciam trabalho produtivo de improdutivo (demonstrando a possibilidade de as ações profissionais serem enquadradas, de uma ou outra forma, a partir do espaço ocupacional, setor público ou privado); destacam a participação do Serviço Social na esfera da reprodução social; reafirmam que a atividade desse trabalhador gera um produto.

As pequenas diferenças aparecem ao final dos textos. Granemann (1999), por exemplo, defende que não existe apenas uma matéria e um instrumento de trabalho do Serviço Social, pois essa profissão possui diferentes processos de trabalho. Logo, a depender das funções desempenhadas, a matéria (questão social, política social, etc.) e os instrumentos se modificam. Já Cardoso et. al. (1997) restringe-se à reprodução quase que integral dos argumentos de Marilda Iamamoto, sustentando, porém, de forma mais categorial do que esta, a existência de um processo de trabalho do Serviço Social. 
Apontamentos mais instigantes foram trazidos por Barbosa, Cardoso e Almeida (1998). No texto publicado na Revista Serviço Social e Sociedade $n^{\circ} 58$, os pesquisadores buscaram elencar novos elementos para a compreensão do Serviço Social, enfatizando a sua caracterização como serviço (fato que Iamamoto e Carvalho (2009) já haviam afirmado, mas não aprofundado).

Para realizar tal empreendimento, Barbosa, Cardoso e Almeida (1998), embora asseverem que é possível tomar o conceito de processo de trabalho (considerando seus elementos básicos) para compreender a atividade do assistente social, utilizam uma concepção um pouco diferente de trabalho. A despeito das obras anteriormente citadas, não partem da tipificação articulada à modificação da natureza, mas apresentam a seguinte definição: "trabalho é aqui compreendido como processo social de transformação que visa a atender necessidades sociais de reprodução humana" (Idem, p. 111). Nota-se que, até pela discussão articulada ao setor de serviços, a transformação citada não se dá necessariamente em objetos naturais ou matérias-primas.

Em vez de identificarem o objeto e os meios de trabalho do assistente social, enquadrando-o no conceito de processo de trabalho em geral, o texto desses escritores se debruça sobre as características do processo de produção de mais-valia, descrevendo as implicações que ele traz para a profissão. Nesse sentido, são destacadas como pontos cruciais para a análise: a desqualificação, a fragmentação, a separação entre gerência e execução e a sujeição da atividade profissional aos critérios de rentabilidade e eficácia.

Além desses fatores, o texto avança ao apontar a necessidade de se "alargar o conceito de processo de trabalho abarcando outros elementos que cumprem uma função de mediação em sua configuração" (Idem p. 117). Para isso, elenca outras dimensões (dentre elas a institucional, a de gestão e a simbólica) como determinantes presentes na execução das funções laborativas. No caso do Serviço Social especificamente, Barbosa, Cardoso e Almeida (1998) ainda chamam a atenção para os mandatos legal e científico conquistados por essa ocupação, visto que ela é regulamentada como liberal e possui autonomia técnica na execução de suas ações. Essa análise suscita a necessidade de se repensar os serviços, e isso inclui a aludida especialização, a partir de parâmetros diferentes daqueles elencados por Marx (2013) na discussão sobre processos de trabalho.

Algumas limitações, porém, são reproduzidas quando se levam em conta as produções de Barbosa, Cardoso e Almeida (1998), Granemann (1999), Cardoso et. al. (1997) e do 
próprio Almeida (1996). Nesse rol, destaca-se a afirmação de que o trabalho do assistente social gera um produto. Como já foi abordado, considerando a classificação de Marx (2013) sobre o tema, seria impertinente asseverar isso. Os resultados da atividade realizada pelo Serviço Social geram, no máximo, efeitos políticos e sociais, não sendo estes produtos, já que não representam o final de um processo de transformação empreendido por esse especialista em objetos concretos (naturais e/ou matérias-primas).

Para melhor elucidar essas questões, a produção de Lessa (2007) oferece elementos completamente novos para a reflexão, pois, na contramão das propostas de Marilda Iamamoto (2010), o autor questiona a necessidade de se pensar o Serviço Social como trabalho, como um requisito indispensável para enfrentar os novos desafios da reestruturação produtiva. Segundo Lessa (2007, p. 96), a estrutura categorial utilizada por Iamamoto (2010) é ambígua e contraditória.

Em primeiro lugar, cabe destacar que, além de não identificar a aludida especialização como parte de um processo de trabalho, o referido escritor sequer a identifica como trabalho. $\mathrm{Na}$ sua concepção, as formulações de Iamamoto (2010) ampliaram essa categoria ao ponto de igualá-la a qualquer atividade humana, visto que a ênfase recai sobre a seguinte característica: dar respostas teleologicamente projetadas às necessidades humanas. Lessa (2007) acredita que esse elemento é comum a todas as ações humanas.

Nesse rumo, o que haveria de específico no trabalho é o intercâmbio que ele possibilita entre o homem e a natureza. Contudo, ao ignorar esse fator primordial, perdendo de vista a diferencialidade entre o trabalho e as demais atividades humanas, Iamamoto (2010) acabaria por tratar indistintamente também os objetos materiais e a objetividade das relações sociais (o natural e o social). Esse movimento leva a professora a afirmar que a questão social é a matéria-prima da profissão, equivocando-se novamente em relação à obra de Marx (2013).

Outro possível problema, já foi abordado neste artigo, refere-se ao chamado produto gerado pelo Serviço Social. Lessa (2007) também não concorda com a existência deste, uma vez que, como todo serviço, a atividade realizada pelo assistente social não se descola do indivíduo, mas se esgota em si mesma. Além disso, na visão desse autor, Iamamoto (2010) define que o chamado produto gerado por essa ocupação seria uma objetividade "não material" que interfere na reprodução material da força de trabalho, o que promove uma dupla contradição: primeiramente porque toda objetividade é material e, só por isso, pode interferir na reprodução da força de trabalho; e, em segundo lugar, porque essa "não materialidade" 
proposta por Iamamoto (2010) se separaria do assistente social, o que não acontece por ser tal ocupação um serviço.

\begin{abstract}
A resposta de Iamamoto à questão de qual seria o produto do Serviço Social é, portanto, contraditória. Postula que, enquanto "serviço", o Serviço Social " tem produto" (Iamamoto, 1998: 69), apesar de haver definido "serviços" como aqueles processos de trabalho "que não se transformam em produtos separáveis de seus produtores". E, desta primeira contradição, evolui para a tese segundo a qual o Serviço Social resultaria em um "produto" o qual, ainda que "não material", "interferiria" na "reprodução material" da força de trabalho. A busca de um "produto" onde não há "produto" (nos serviços, e especificamente no Serviço Social) termina conduzindo o texto a uma posição teoria mais débil, qual seja, a concepção do mundo dos homens enquanto uma dualidade ontológica. Haveria no ser social uma porção material e, outra, não material (LESSA, 2007: 99 e 100).
\end{abstract}

Por último, Lessa (2007) questiona a noção segundo a qual o assistente social é parte de um "trabalhador coletivo". Na sua visão, o trabalhador coletivo, para Karl Marx, corresponde apenas ao segmento dos assalariados que exercem a função social de intercâmbio com a natureza (Idem, p. 100), o que não é o caso do assistente social. Nessa direção, volta a criticar Iamamoto (2010) por incluir nessa denominação as mais diversas atividades e formas de trabalho (produtivas e improdutivas) sem as distinções que lhes são devidas.

A grande limitação de Lessa (2007), todavia, é não considerar as atividades vinculadas ao setor de serviços como trabalho, detendo-se a pensá-lo apenas como intermediador entre o homem e a natureza. Nesse ponto, a posição aqui adotada converge com a de Barbosa, Cardoso e Almeida (1998), quando citam passagens das produções marxianas, em especial Marx (2004), para exemplificar um conjunto de atividades laborativas que, embora não realizem mudanças em objetos materiais nem participem de processos de trabalho nos moldes da tipologia clássica (MARX, 2013), são trabalho, podendo, inclusive, produzir valor.

\title{
Considerações Finais
}

Como se tentou demonstrar, existem diferentes opiniões (algumas mais próximas, outras mais contrastantes) acerca da relação entre o Serviço Social e a categoria marxiana processo de trabalho. No entanto, o que chama atenção nessas discussões, para além do fato de estarem recorrentemente ocupando espaços nos textos, encontros e seminários em que os principais representantes intelectuais da categoria participam, é o distanciamento entre as abordagens apresentadas e o cotidiano concreto dos assistentes sociais. Em nenhuma das 
produções, é possível verificar uma análise do trabalho profissional a partir da realidade, das tarefas, das atribuições e dos instrumentais que envolvem a intervenção em Serviço Social.

De fato, o que se visualiza nas produções é mais um esforço teórico de se aprofundarem as investigações sobre o significado e as funções históricas do Serviço Social no interior das relações entre as classes, do que uma preocupação com a forma e os caminhos da prática profissional (seja ela trabalho, práxis, prática, atividade, complexo). Nesse sentido, não pode ser o domínio desse conteúdo, como pensou Iamamoto (2010), um requisito indispensável para os assistentes sociais. Na realidade, a tendência que se aponta é a de que o referido debate pode estar promovendo mais confusões do que elucidações no imaginário de uma categoria que, como apontaram Torres (2007) e Felippe (2013), não conhece sequer as tarefas e as prerrogativas inerentes ao seu cargo.

Por outro lado, considerando a trajetória intelectual dos principais autores que versam sobre o assunto, é possível tecer algumas observações indicativas. No caso de Iamamoto (2004, 2010 e 2012) e dos autores que reafirmam com maior nitidez a posição teórica por ela inaugurada, Granemann (1999) e Cardoso et. al. (1997), a defesa da tese do Serviço Social como especialização do trabalho coletivo e a busca por uma estrutura conceitual que fundamentasse tal posicionamento poderiam estar associadas à tentativa de consolidar essa concepção como elemento das Diretrizes Curriculares da ABEPSS

Os fundamentos teóricos foram encontrados na associação entre a atividade do Serviço Social e os elementos do processo de trabalho em geral formulados por Marx (2013). Como foi visto, porém, essa aproximação, sem as devidas distinções entre as funções desempenhadas por um trabalhador que confecciona objetos materiais e um trabalhador do ramo de serviços, gerou uma série de ambiguidades nos textos Iamamoto (2004, 2010 e 2012), Granemann (1999) e Cardoso et. al. (1997). Algumas foram aqui desvendadas; outras, evidenciadas por Lessa (2007).

Também merece destaque o artigo de Barbosa, Cardoso e Almeida (1998), o qual possibilita uma aproximação mais substancial entre a profissão e o ramo dos serviços. Apesar disso, algumas limitações são aqui encontradas, dentre elas destacam-se: a manutenção das noções de objeto e a compreensão do assistente social como componente do trabalhador coletivo.

Nessa linha, alguns caminhos se abrem para que o Serviço Social, como uma atividade situada no ramo dos serviços, possa ser compreendido como trabalho, mas não nos moldes da 
categoria processo de trabalho em Marx (com meios, objeto e produto). Não gerando bens concretos ou modificando objetos materiais, os efeitos úteis das ações desempenhadas pelo assistente social são de caráter social e político, restringindo-se à esfera da reprodução social (o que não significa ausência de vínculos com a esfera da produção).

Esses e outros pontos foram abordados neste artigo. Entretanto, em momento algum houve a pretensão de esgotar um assunto que vem mobilizando tantos esforços e intelectuais da profissão. Ao contrário, o que se pretendeu foi expor e problematizar alguns dos dilemas, embates e limitações que envolvem a "leitura" da profissão de Serviço Social por meio da categoria processo de trabalho.

\title{
PROCESO DE TRABAJO Y TRABAJO SOCIAL: DILEMAS, CONFLICTOS Y LIMITACIONES
}

\section{Resumen}

Tomando la categoría proceso de trabajo en marx como punto de partida, este artículo rescates algunas de las principales aproximaciónes entre este marco conceptual y de la profesión de trabajo social. Con este fin, se analizaron las producciones de los principales intelectuales (iamamoto, 2010; almeida, 1996; barbosa, cardoso e almeida, 1998; granemann, 1999; cardoso et. Al. 1997; lessa, 2007) que propusieron para discutir el tema, destacando las limitaciones, los conflictos y los dilemas de sus obras. Al mismo tiempo, el texto regresa a los elementos clásicos de la tipología marxista, así como al debate sobre el sector de servicios para demostrar las debilidades de algunas de estas apropiaciones y apuntar nuevos caminos de reflexión.

Palabras clave: trabajo social; proceso de trabajo; servicios.

\section{WORK PROCESS AND SOCIAL WORK: DILEMMAS, CLASHES AND LIMITATIONS}

\begin{abstract}
Taking the work process category in Marx as a starting point, this article rescues some of the key approximations between this conceptual framework and social work profession. For this, the productions of leading intellectuals (iamamoto, 2010; almeida, 1996; barbosa, cardoso e almeida, 1998; granemann, 1999; cardoso et. Al. 1997; lessa, 2007) who discussed the topic, highlighting the limitations, the conflicts and the dilemmas of his works were analyzed. Concurrently, the text rescues the classic elements of the marxian typology, as well as the debate on the service sector to demonstrate the weaknesses of some of these approaches and to point new reflective paths.
\end{abstract}


Keywords: Social Work; work process; services.

\section{REFERÊNCIAS}

ALMEIDA, N. L. Considerações iniciais para o exame do processo de trabalho do Serviço Social. In: Serviço Social e Sociedade. São Paulo: Cortez, nº 52, p. 24-47, 1996.

BARBOSA, R. N.; CARDOSO, F. G.; ALMEIDA, N. L. A categoria processo de trabalho e o trabalho do assistente social. In: Serviço Social e Sociedade. São Paulo: Cortez, nº 58, p. 109130, 1998.

BRAVERMAN, H. Trabalho e capital monopolista: a degradação do trabalho no século XX. Rio de Janeiro: LTC, 1987.

CARDOSO. et. al. Proposta básica para o projeto de formação profissional - novos subsídios para o debate. In: Cadernos ABESS. São Paulo: Cortez, nº 7, p. 15-57, 1997.

CFESS. Assistentes Sociais no Brasil: Elementos para o estudo do perfil profissional. Brasília, 2005.

COSTA, M. D. H. Os serviços na contemporaneidade: notas sobre o trabalho nos serviços. In: MOTA, A. E. (Org.). A nova fábrica de consensos. São Paulo: Cortez, 2010.

FALEIROS, Vicente de Paula. Estratégias em Serviço Social. São Paulo: Cortez, 1997.

FELIPPE, J. Projetos profissionais do Serviço Social e da Psicologia nos CRAS: uma articulação bem sucedida? In: Vértices. Campos dos Goytacazes: Essentia, v.15, n. 1, p. 97$111,2013$.

GRANEMANN, S. Processos de trabalho e Serviço Social. In: CFESS e ABEPSS. Reprodução Social, trabalho e Serviço Social: capacitação em Serviço Social e Política Social. Brasília: CEAD/UNB, p. 153-166, 1999.

IAMAMOTO, M.; CARVALHO, R. Relações sociais e Serviço Social no Brasil: esboço de uma interpretação histórico-sociológica. São Paulo: Cortez/Celats, 2009.

IAMAMOTO. M. Renovação e conservadorismo no Serviço Social: ensaios críticos. São Paulo: Cortez, 2004.

O Serviço Social na contemporaneidade: trabalho e formação profissional. São Paulo: Cortez, 2010. 
Serviço Social em tempo de capital fetiche: capital financeiro, trabalho e questão social. São Paulo: Cortez, 2012.

LESSA. S. Trabalho e proletariado no capitalismo contemporâneo. São Paulo: Cortez, 2007.

MANDEL, E. O Capitalismo tardio. São Paulo: Nova Cultural, 1985.

MARX, K. O capital: crítica da economia política. Rio de Janeiro: Civilização Brasileira, Livro I, 2013.

Trabalho produtivo e trabalho improdutivo. In: ANTUNES, R. A dialética do trabalho. São Paulo: Expressão popular, 2004.

NETTO, J. P. Capitalismo monopolista e Serviço Social. São Paulo: Cortez, 2007.

TORRES, Mabel. Atribuições privativas presentes no exercício profissional do assistente social: uma contribuição para o debate. In: Libertas. Juiz de Fora: UFJF, v. 1, n. 2, p. 42-69, 2007.

Data de recebimento: $10 / 03 / 14$

Data de aceite: $27 / 07 / 16$

\section{Sobre os autores:}

Jonis Manhães Sales Felippe é Graduado em Serviço Social pela Universidade Federal Fluminense (UFF) e mestrando em Serviço Social pela Universidade do Estado do Rio de Janeiro (UERJ).

Isabela Sarmet de Azevedo é Mestra e Doutora em Serviço Social pela Pontifícia Universidade Católica de São Paulo (PUC/SP). Professora adjunta da Universidade Federal Fluminense (UFF). 